\title{
ANTHROPEN
}

Le dictionnaire francophone d'anthropologie ancré dans le contemporain

\section{ANTHROPOLOGIE ET PSYCHANALYSE}

\author{
Lézé, Samuel \\ ENS Lyon, France
}

Date de publication : 2021-06-11

DOI : https://doi.org/10.47854/anthropen.vi0.51158

Voir d'autres entrées dans le dictionnaire

Les rapports entre anthropologie et psychanalyse ont suscité deux grands débats théoriques : comment développer le projet général des « sciences de l'esprit » humain ? Et, dans ce programme, quel est le statut spécifique de la psychanalyse ?

Le premier débat soulève la question de l'interdisciplinarité pouvant converger ou non vers un paradigme de " science de l'esprit », c'est-à-dire une anthropologie au sens large du terme, une science de l'être humain. Sigmund Freud (1856-1939) postule ainsi que l'histoire individuelle récapitule l'histoire de l'espèce humaine. C'est pourquoi il emprunte des matériaux et des concepts (mythe, totem, tabou, etc.) à l'anthropologie évolutionniste de son époque, selon une série d'analogies entre l'enfant, le primitif et le névrosé, ou entre le rêve et le mythe (Rosa 2003). Pour un individu, surmonter le " complexe d'OEdipe » est, contrairement au névrosé, évoluer vers la maturité dans une phase clé de son développement psychosexuel qui est aussi la matrice de la morale collective. Le « retour à Freud » de Jacques Lacan (1901-1981) se fonde également sur des concepts de l'anthropologie de son époque, structuraliste, pour démédicaliser la psychanalyse (Zafiropoulos 2003) selon l'analogie de l'inconscient structuré comme un langage. Freud développe une théorie critique de la culture se fondant, là encore, sur des analogies cliniques : par exemple, la critique de la religion se fonde sur la clinique des névroses obsessionnelles en faisant du « rite " un dénominateur commun. La névrose obsessionnelle est ainsi un rite privé et individuel et le rite religieux, une névrose obsessionnelle publique et collective. La théorie critique de la culture de Lacan est plus radicale car le langage est le lieu de la culture et de la loi. Le sujet de l'inconscient est donc collectif, il révèle le malaise dans la civilisation.

C'est l'approche interdisciplinaire entre la psychologie et l'anthropologie sur des problèmes communs (les conditions et les effets de la socialisation des enfants, 
notamment), plus que les théories freudiennes elles-mêmes, qui inspire diverses études sur les rapports entre "culture et personnalité " aux élèves de Franz Boas (1858-1942) et, plus largement, à l'anthropologie nord-américaine qui, entre 1918 et 1960, se consacre tantôt au développement de la personnalité dans la culture, tantôt à la spécificité des caractères nationaux. Renommée depuis « anthropologie psychologique » pour s'organiser en domaine relativement autonome de l'Association américaine d'anthropologie, la phénoménologie (c'est-à-dire la description des expériences) s'y est progressivement substituée aux allusions au freudisme (LeVine 2001).

Ce débat se clôt ordinairement par une application d'une discipline à l'autre en en mobilisant une version unilatérale et restreinte. Soit l'interprétation psychanalytique est appliquée aux matériaux ethnographiques dans diverses variantes de « l'anthropologie psychanalytique », sur le modèle de la " défense et illustration » de l'universalité des théories du mental de la psychanalyse (Roheim 1967), avec, par exemple, le «travail individuel de la culture " (Obeyesekere 1990) et les enjeux du transfert des affects dans le travail de terrain (Mimica 2007); soit le savoir anthropologique, vu comme un stock de matériaux culturels, est appliqué à la conduite d'une psychothérapie dans diverses variantes cliniques de « l'ethnopsychiatrie », loin de mettre en oeuvre l'idéal de "complémentarité " (Deveureux 1972). Rares sont alors les monographies ethnographiques qui s'illustrent par un enrichissement de la psychanalyse. C'est le cas dans Les mots, la mort, les sorts, qui envisage la sorcellerie dans le bocage normand comme un langage, à savoir un jeu d'assignations de places dans un système symbolique et de production d'affects, car l'ethnographe n'a rien d'autre à observer sur son terrain que des situations d'interlocution (Favret-Saada 1977).

Le second débat soulève la question de l'universalité des théories de la psychanalyse et donc du statut culturel de la psychanalyse dans nos sociétés. Le cycle est ouvert dès 1923 par Bronislaw Malinowski (1884-1942). À partir de l'étude comparée de la parenté, il soutient que Freud théorise le complexe d'œEdipe à partir des effets locaux de la famille "nucléaire " occidentale (père-mère-enfants avec un habitat commun), en identifiant le père biologique à la fonction d'autorité. Pour autant, l'observation des comportements manifestes concernant les relations de parenté et de sexualité sur son terrain mélanésien aux îles Trobriand ne lui permet pas d'analyser la dimension latente que prétend dévoiler la psychanalyse, mais met en évidence un " complexe » spécifique aux Trobriandais s'appuyant sur l'oncle maternel (Pulman 2002). Cependant, lorsque Lacan procède à la distinction entre le géniteur (la biologie) et la fonction paternelle (la culture), il concilie ainsi la psychanalyse avec la pluralité des systèmes de parenté.

De nombreuses variantes de cette objection anthropologique ont été développées par la suite, en bénéficiant d'une meilleure connaissance des théories et des pratiques de la psychanalyse: celle qui relève la dimension a-historique ou essentialiste du « primitif » chez Freud dans la perspective des études postcoloniales (Brickman 2003), ou bien encore celle qui se base sur le « symbolique » chez Lacan pour penser la famille contemporaine dans la perspective des études de genre (Robcis 2016). De même, les applications unilatérales de l'anthropologie à la psychanalyse 
des immigrés et des migrants peuvent essentialiser la culture d'un patient en raison de son origine (Fassin 2000). Enfin, les applications de la psychanalyse à l'ethnographie de sociétés réputées exotiques isolent des objets supposés énigmatiques (contes, mythes, rites, énoncés paradoxaux, etc.), pour en fournir des explications par le mental et une surinterprétation du « sens " ne produisant aucun savoir anthropologique nouveau (Lézé 2005).

Loin de se clore, ce débat s'est transformé en programme empirique. D'objet critique se focalisant sur la théorie et les textes de Freud ou de Lacan, la psychanalyse est progressivement devenue objet d'étude ethnographique dans une perspective d'anthropologie médicale se focalisant sur les croyances et les pratiques des freudiens et des lacaniens. La première tentative, avortée, portait sur la Société britannique de psychanalyse. Donald Winnicott (1896-1971) président de l'époque, en avait refusé le principe. Elle a néanmoins permis de tirer une leçon méthodologique importante pour les études suivantes: l'accès aux sociétés de psychanalystes implique un coût d'entrée élevé. Cette clôture et cette opacité sont faciles à dénoncer et à moquer faute de matériaux ethnographiques sur les raisons de cette croyance (Gellner 1990). Cependant, encore faut-il, d'une part, en expliquer les raisons à partir du sens que peuvent bien donner les freudiens à l'idée d'incommensurabilité de la cure et d'extraterritorialité de leurs sociétés ; et, d'autre part, trouver le rôle que l'ethnographe peut y tenir légitimement, comme pour tout autre terrain.

Une des raisons de cette difficulté tient à la nature de la formation, lieu de conflits et de divisions chroniques, qui relève plutôt de la transmission et donc de filiations. Cet aspect est manifeste dans l'ethnographie de la formation des psychiatres américains qui se divisaient sur la conception de l'esprit et de la personne (Luhrman 2000). Ainsi, les freudiens, critiques de la biomédicalisation de la psychiatrie, ont été étudiés en Argentine (Lakoff 2008), au Brésil (Béhague 2009), en France (Lézé 2010) et aux États-Unis (Schechter 2014). Et c'est aussi en commençant par la question de la formation comparée des psychothérapeutes en Grande-Bretagne que la psychanalyse britannique a fait finalement l'objet d'une ethnographie (Davies 2018). Pour autant, les conceptions de l'esprit humain ne se manifestent pas uniquement dans la pratique et les jugements cliniques des psychiatres et des psychologues. Car cette autorité clinique est aussi culturelle. Ces conceptions sont donc aussi à l'œuvre dans les polémiques médiatisées entre freudiens et anti-freudiens, comme le montre l'analyse culturelle de l'icône Freud aux États-Unis et en France (Lézé 2017).

\section{Références}

Béhague D.P. (2009), « Psychiatry and politics in Pelotas, Brazil: The equivocal uses of "conduct disorder" and related diagnoses ». Medical Anthropology Quarterly, vol.23, n4, p.455-482.

https://doi.org/10.1111/j.1548-1387.2009.01073.x

\section{Brickman, C. (2003), Aboriginal populations in the mind: Race and primitivity in psychoanalysis. New York, Columbia University Press. https://doi.org/10.7312/bric12582}


Davies, J. (2018), The making of psychotherapists: An anthropological analysis. Londres, Routledge.

https://doi.org/10.4324/9780429482373

Devereux, G. (1972), Ethnopsychanalyse complémentariste. Paris, Flammarion.

Fassin, D. (2000), « Les politiques de l'ethnopsychiatrie. La psyché africaine, des colonies africaines aux banlieues parisiennes ". L'homme, n¹53, p.231-250. https://doi.org/10.4000//homme.14

Favret-Saada, J. (1977), Les mots, la mort, les sorts. Paris, Gallimard.

Gellner, E. (1990), La ruse de la déraison. Le mouvement psychanalytique. Paris, Presses universitaires de France.

Lakoff, A. (2008), La raison pharmaceutique. Paris, Les Empêcheurs de penser en rond.

Lézé, S. (2005), « Le sens de l'équivoque. Les usages de la psychanalyse en anthropologie ». Anthropologie et sociétés, vol.29, n¹, p.205-214.

https://doi.org/10.7202/011747ar

Lézé, S. (2010), L’autorité des psychanalystes. Paris, Presses universitaires de France.

Lézé, S. (2017), Freud Wars. Un siècle de scandales. Paris, Presses universitaires de France. https://doi.org/10.3917/puf.samue.2017.03

LeVine, R.A. (2001), « Culture and personality studies, 1918-1960: Myth and history ». Journal of Personality, vol.69, n6, p.803-818.

https://doi.org/10.1111/1467-6494.696165

Luhrmann, T.M. (2000), Of two minds: An anthropologist looks at American psychiatry. New York, Alfred A. Knopf.

Mimica, J. (dir.) (2007), Explorations in psychoanalytic ethnography. Oxford et New York, Berghahn Books.

Obeyesekere, G. (1990), The work of culture: Symbolic transformation in psychoanalysis and anthropology. Chicago, University of Chicago Press.

Pulman, B. (2002), Anthropologie et psychanalyse. Malinowski contre Freud. Paris, Presses universitaires de France. https://doi.org/10.3917/puf.pulma.2002.01

Robcis, C. (2016), La loi de la parenté. La famille, les experts et la République. Paris, Fahrenheit. 
Róheim, G. (1967), Psychanalyse et anthropologie. Paris, Gallimard.

Rosa, F. (2003), L'âge d'or du totémisme. Histoire d'un débat anthropologique (18871929). Paris, CNRS éditions.

https://doi.org/10.4000/books.editionscnrs.2074

Schechter, K. (2014), Illusions of a Future: Psychoanalysis and the Biopolitics of Desire. Durham, Duke University Press.

https://doi.org/10.1215/9780822376422

Zafiropoulos, M. (2003), Lacan et Lévi-Strauss ou le retour à Freud, 1951-1957. Paris, Presses universitaires de France.

https://doi.org/10.3917/puf.zafir.2003.01 